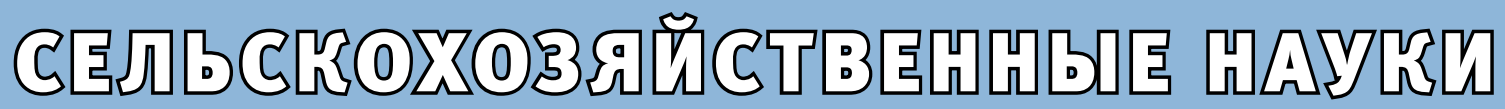

удк 636:612+636.4

\section{ГОРМОНАЛЬНЫЙ СТАТУС И ПРОДУКТИВНЫЕ КАЧЕСТВА МОЛОДНЯКА СВИНЕЙ ПРИ ВКЛЮЧЕНИИ В РАЦИОН КОРМЛЕНИЯ ГОМОГЕНАТА ТРУТНЕВОГО РАСПЛОДА}

ЗДОРОВЬЕВА Елена Валерьевна, Пензенский государственный аграрный университет БОРЯЕВ Геннадий Иванович, Пензенский государственный аграрный университет НОСОВ Алексей Викторович, Пензенский государственный аграрный университет КАТАЕВ Олег Геннадьевич, Пензенский государственный аграрный университет МЕЛОЯН Гаянэ Мкртичевна, Пензенский государственный аграрный университет ЗЕМЛЯНОВА Юлия Валериевна, Пензенский Областной онкологический диспансер КИСТАНОВА Елена Кузьминична, Институт биологии и иммунологии размножения при Болгарской Академии Наук

Изучено влияние гомогената трутневого расплода на уровень тестостерона и кортизола свинок, а также на их продуктивные параметры. Включение гомогената трутневого расплода в рацион свинок повлияло на их гормональный статус, скорость роста, о чем свидетельствует повышение таких показателей, как живая масса, среднесуточный прирост, процент убойного въхода животных.

Введение. Высокая продуктивность животных обусловлена интенсивными обменными процессами, протекающими в их организме. В кормлении свиней применяются биологически активные вещества различной природы, способствующие повышению усвоения питательных веществ корма. Благодаря продолжению работы по усовершенствованию генетики у современных пород свиней имеется значительный потенциал скорости роста по сравнению с породами, выведенными более десяти лет назад. Необходимо максимизировать биологические преимущества организма свиней через кормление таким образом, чтобы использовать весь потенциал в полной мере. Важно понимать, что кормление должно реализовывать биологический потенциал свиней не в одной стадии откорма, а на протяжении всего цикла жизни от отъема до убоя [2].

Гомогенат трутневого расплода наряду с другими биологически активными веществами имеет широкий спектр биологической активности, в том числе и воздействие на эндокринную систему [4]. Исследования ряда ученых показали, что он может служить источником белка, богатого незаменимыми аминокислотами, жирами, углеводами, а также ферментами, стеролами, витаминами, макро- и микроэлементами, гормонами и непредельными соединениями и другими физиологически важными компонентами $[1,6,8]$.

Цель данной работы - изучение гормонального статуса организма молодняка свиней и их продуктивных параметров при включении в рацион гомогената трутневого расплода.

Методика исследований. В условиях вивария ФГБОУ ВО Пензенский ГАУ в 20152016 гг. был проведен научный эксперимент на молодняке свиней крупной белой породы. Для этого были сформированы три группы свинок-аналогов в возрасте 35 суток по десять голов в каждой группе: контрольная основной рацион; І опытная - с основным рационом получали гомогенат трутневого расплода в дозе 25 мг сухого вещества на 1 кг корма; II опытная - гомогенат трутне- 
вого расплода в дозе 25 мг сухого вещества на 1 кг корма и селенопиран в дозе 1,2 мг на 1 кг корма.

Продолжительность эксперимента составила 140 дней. В ходе него у животных отбирали кровь из хвостовой артерии, проводили индивидуальные взвешивания, определяли живую массу, среднесуточный прирост живой массы, убойный выход по общепринятым в зоотехнии методикам.

Лабораторные исследования проводили в межфакультетской биохимической лаборатории. Для количественного определения тестостерона и кортизола в сыворотке крови свинок использовали метод твердофазного иммуноферментного анализа. Проводили вычисление среднего значения, стандартного (среднеквадратичного) отклонения и стандартной ошибки среднего. Различия средних значений после эксперимента между опытными и контрольной группами сравнивали путем вычисления критерия Стьюдента.

Результаты исследований. В ходе научного эксперимента по изучению влияния гомогената трутневого расплода на гормональный статус молодняка свиней было установлено, что в возрасте 35 суток уровень тестостерона в крови свинок составлял $3,27 \pm 0,251-3,38 \pm 0,208$ нмоль/л. К 175-суточному возрасту наблюдалось снижение концентрации тестостерона во всех исследуемых группах (табл. 1, рис. 1). У контроль- ных животных этот показатель снизился в 3 раза, в опытной группе I в 2,4 раза и в опытной группе II в 1,8 раза.

В начале эксперимента уровень тестостерона у животных всех групп был на одинаковом уровне. В возрасте 115 суток у свинок, получавших гомогенат трутневого расплода, концентрация тестостерона составила $1,09 \pm 0,129$ нмоль/л, что статистически значимо ниже по сравнению с данными контрольной и II опытной группами. Возможно, различия объясняются поступлением извне в организм молодняка эндогенных гормонов. Установлено, что трутневый расплод содержит половые гормоны - тестостерон, эстрадиол, прогестерон, пролактин, ФСГ И ЛГ [4]. В исследованиях M. Auezov, M. Utemisov, Z. Khan показано, что трутневый расплод содержит достаточное количество биологически активных веществ и природных гормонов, которые не вызывают существенных изменений гормонального статуса животных [7]. Возможно, введение в рацион кормления свинок трутневого расплода несколько снизило выработку собственного гормона в организме. Известно, что недостаток тестостерона в женском организме приводит к уменьшению мышечной массы, замедлению обмена веществ, увеличению жировой ткани. Несмотря на то, что уровень тестостерона в организме свинок I опытной группы ниже по сравнению с контрольной и II опытной группами нельзя го-

Таблица 1

Концентрация гормонов в крови молодняка свиней, нмоль/л

\begin{tabular}{|c|c|c|c|c|c|c|}
\hline \multirow{2}{*}{ Группа } & \multicolumn{5}{|c|}{ Возраст } \\
\cline { 2 - 7 } & \multicolumn{2}{|c|}{35 суток } & \multicolumn{2}{|c|}{115 суток } & \multicolumn{2}{c|}{175 суток } \\
\cline { 2 - 7 } & тестостерон & кортизол & тестостерон & кортизол & тестостерон & кортизол \\
\hline \multirow{2}{*}{ Контрольная } & $3,38 \pm 0,208$ & $1411 \pm 79$ & $1,60 \pm 0,123$ & $427 \pm 26$ & $1,15 \pm 0,041$ & $595 \pm 45$ \\
\hline І опытная & $3,27 \pm 0,251$ & $1425 \pm 57$ & $1,09 \pm 0,129^{* *}$ & $547 \pm 36$ & $1,36 \pm 0,087$ & $1188 \pm 69^{*}$ \\
\hline ІІ опытная & $3,29 \pm 0,145$ & $1379 \pm 138$ & $1,74 \pm 0,047$ & $721 \pm 63^{*}$ & $1,82 \pm 0,092^{*}$ & $1320 \pm 35^{*}$ \\
\hline
\end{tabular}

* статистически значимая разница относительно контрольной группы (здесь и далее); \# статистически значимая разница относительно II опытной группы. 
ворить о его недостатке в организме. Анализ показателей продуктивности молодняка свиней свидетельствует о том, что живая масса, среднесуточный прирост и качественные показатели мяса в I опытной группе были выше относительно аналогичных показателей в других группах.

В группе молодняка свиней, получавших трутневый расплод с селенопираном, установлено повышение уровня тестостерона относительно контроля и I опытной группы. Возможно, что включение селенопирана позволило повысить данный показатель. Установлено, что введение селенопирана в рацион кормления лабораторных животных повышает уровень тестостерона в крови [5].

Включение трутневого расплода в рацион кормление молодняка свиней повлияло на активность гормона кортизола (см. табл. 1, рис. 2). В возрасте 35 суток концентрация кортизола в крови свинок составляла от $1379 \pm 138$ до $1425 \pm 57$ нмоль/л. К 115-суточному возрасту уровень кортизола снизился во всех изучаемых группах, а к 175-м суткам увеличился. Установлено статистически значимое повышение концентрации кортизола в 115 суток у

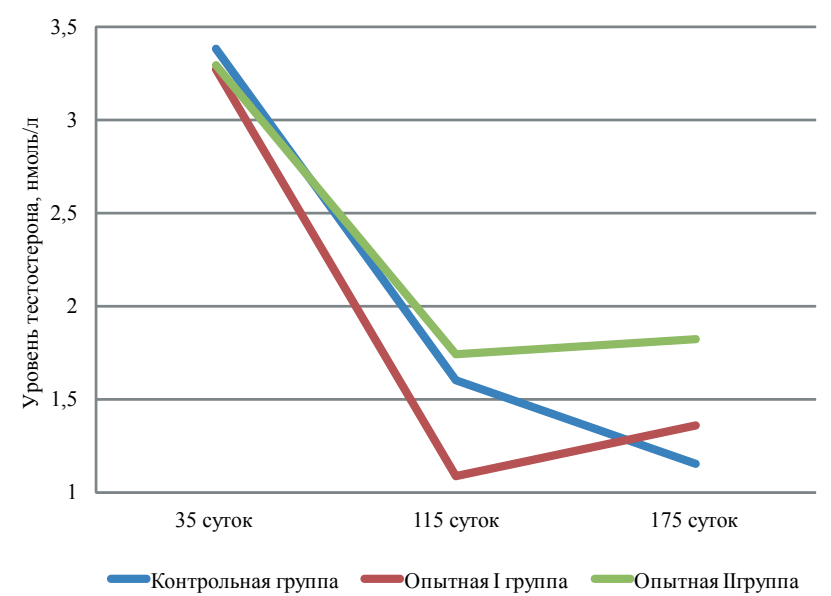

Рис. 1. Динамика кониентрации тестостерона в крови свинок

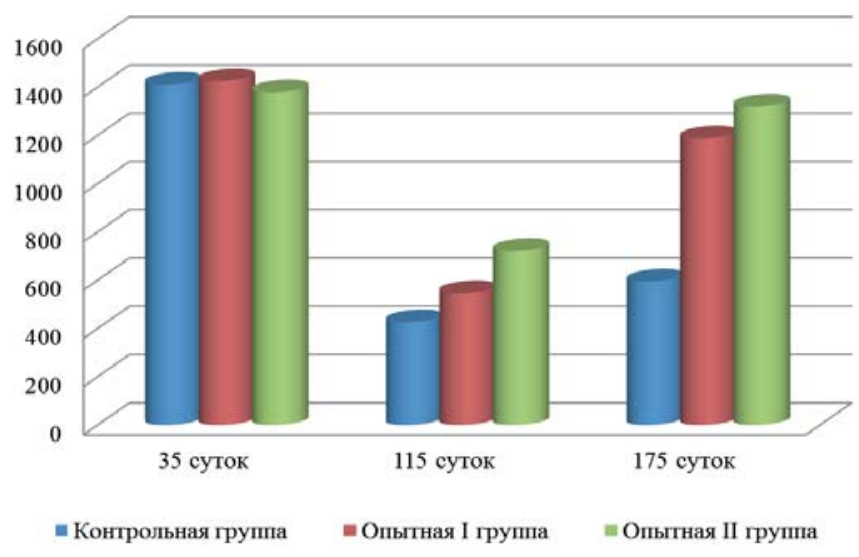

Рис. 2. Уровень кортизола в крови свинок животных II опытной группы относительной контрольной и I опытной групп. К 175-м суткам концентрация кортизола повышалась как в I, так и во II опытных группах.

Высокий уровень кортизола в крови свинок в начальный период эксперимента, возможно, связан с адаптацией животных. В возрасте 175 суток концентрация кортизола у свинок I опытной группы составила $1188 \pm 69$ нмоль/л, а у животных II опытной группы $1320 \pm 35$ нмоль/л, что статистически значимо выше по сравнению с контролем. Вероятно, это связано с более интенсивными процессами метаболизма, протекающими под воздействием андрогенов гомогената трутневого расплода.

Полученные данные свидетельствуют о том, что трутневый расплод является хорошим стимулятором эндогенных механизмов синтетических процессов в организме молодняка свиней. Результаты исследований показали, что введение в рацион свинок гомогената трутневого расплода статистически значимо повышает процент убойного выхода животных (табл. 2).

Включение в рацион кормления гомогената трутневого расплода в качестве природного стимулятора повлияло на скорость роста свинок (табл. 3). Данные, представленные в табл. 3, показывают, что в возрасте 175 суток живая масса животных I опытной группы выше по сравнению с контрольной группой. Применение гомогената трутневого расплода в кормлении молодняка свиней позволило повысить среднесуточный прирост. B I опытной группе он выше на 4,27\% по сравнению с контролем и на 5,35 \% по сравнению с II опытной группой. Однако при комплексном применении гомогената трутневого расплода и селенопирана аналогичного эффекта не наблюдалось.

Наши исследования согласовываются с данными M. Auezov, M. Utemisov, Z. Khan и Д.С. Лазарян [3, 7], свидетельствующими о том, что трутневый расплод оказывает анаболическое и актопротекторное действие на организм сельскохозяйственных и лабораторных животных.

Заключение. В результате проведения научного эксперимента установлено стимулирующие влияние трутневого расплода на гормональные показатели и продуктивные параметры молодняка свиней. Это позво- 
Показатели убойного выхода и длины туловища при использовании концентрата трутневого расплода в кормлении молодняка свиней

\begin{tabular}{|c|c|c|}
\hline Группа & Убойный выход, \% & Длина туловища, см \\
\hline Контрольная & $75,3 \pm 0,892$ & $108 \pm 1,057$ \\
\hline І опытная & $78,1 \pm 0,538^{*}$ & $113 \pm 0,973$ \\
\hline ІІ опытная & $76,5 \pm 0,467$ & $109 \pm 1,221$ \\
\hline
\end{tabular}

Таблица 3

\section{Показатели скорости роста молодняка свиней}

\begin{tabular}{|c|c|c|c|}
\hline Группа & $\begin{array}{c}\text { Живая масса в начале } \\
\text { эксперимента, кг }\end{array}$ & $\begin{array}{c}\text { Живая масса в конце } \\
\text { эксперимента, кг }\end{array}$ & Среднесуточный привес, г \\
\hline Контрольная & $10,9 \pm 0,512$ & $92,3 \pm 2,21$ & $585 \pm 7,34$ \\
\hline І опытная & $10,8 \pm 0,567$ & $97,7 \pm 2,18$ & $625 \pm 6,91$ \\
\hline II опытная & $11,7 \pm 0,468$ & $93,1 \pm 2,85$ & $579 \pm 7,34$ \\
\hline
\end{tabular}

лило повысить среднесуточные приросты животных. Таким образом, применение гомогената трутневого расплода в кормлении молодняка свиней позволит более полно реализовать генетический потенциал скорости роста животных.

\section{СПИСОК ЛИТЕРАТУРЫ}

1. Будникова Н.В. Биологически активные соединения в трутневом расплоде // Пчеловодство. -2009 . - № 6. - С. 52-53

2. Влияние трутневого расплода на физиолого-биохимический статус молодняка свиней / Е.К. Кистанова [и др.] // Нива Поволжья. 2016. - № 4. - С. 24-29.

3. Лазарян Д.С. Таблетки «Апилар» на основе трутневого расплода, обладающие анаболическим, актопротекторным действием // Патент № 2233666. - 2004.

4. Митрофанова Д.В., Будникова Н.В., Бурмистрова Л.А. Гормоны трутневого расплода медоносных пчел разного возраста // Пчеловодство. 2015. - № 7. - C. 58-59.

5. Опыт применения трутневого расплода в экспериментах и клинических испытаниях: итоги и перспективы / Ю.В. Землянова [и др.] // Современные аспекты воспроизводства сельско- хозяйственных животных: материалы Междунар. науч.-практ. конф. - Пенза:РИО ПГСХА, 2015. - C. 86-91.

6. Прохода И.А. Получение апидобавок из личинок пчел // Пчеловодство. - 2009. - № 8. С. $48-49$.

7. Auezov M., Utemisov M., Khan Z. Improving Reproductive Qualities of Pigs Using the Drone Brood Homogenate // Bolatovna et al. Biol Med (Aligarh), 2015, No. 7(2).

8. Hrassningg N., Crailsheim R. Differences in the drone and worker physiology in honeybees (Apis mellifera) //Apidologie, 2005, No. 36, P. 255-277.

Здоровьева Елена Валерьевна, канд. биол. наук, дочент кафедры «Биология, биологчческие технологии и ветсанэкспертиза», Пензенский государственный аграрный университет. Россия

Боряев Геннадий Иванович, д-р биол. наук, проф., зав. кафедрой «Биология, биологические технологии и ветсанэкспертиза», Пензенский государственный аграрный университет. Россия.

Носов Алексей Викторович, канд. экон. наук, доизент кафедры «Финансы», Пензенский государственный аграрный университет. Россия.

Катаев Олег Геннадьевич, аспирант кафедры «Биология, биологчческие технологии и ветсанэкспертиза», Пензенский государственный аграрный универcuтет. Россия. 
Мелоян Гаянэ Мкртичевна, студентка технологического факультета, Пензенский государственный аграрный университет. Россия.

440014, г. Пенза, ул. Ботаническая, 30.

Тел.: (8412) 628-359.

Землянова Юлия Валериевна, канд. биол. наук, Пензенский Областной онкологический диспансер. Россия.

440071, г. Пенза, просп. Строителей, 37А.

Тел.: (8412) 41-30-55.
Кистанова Елена Кузьминична, канд. биол. наук, доцент, Институт биологии и иммунологии размножения при Болгарской Академии Наук. Болгария.

73, Цариградско шосе.

1113 София, Болгария.

Тел.: +359898225520; e-mail: kistanova@gmail.com.

Ключевые слова: гомогенат трутневого расплода; свинки; тестостерон; кортизол; живая масса; среднесуточный прирост.

\title{
HORMONAL STATUS AND PRODUCTIVE QUALITIES OF YOUNG PIGS AT INCLUSION IN A DIET FEEDING HOMOGENATE DRONE BROOD
}

Zdorovyeva Elena Valer'evna, Candidate of Biological Sciences, Associate Professor of the chair "Biology, Biological Technology and Veterinary-sanitarian Expertise”, Penza State Agrarian University. Russia.

Boryaev Gennady Ivanovich, Doctoe of Biological Sciences, Professor, Head of the chair "Biology, Biological Technology and Veterinary-sanitarian Expertise", Penza State Agrarian University. Russia.

Nosov Alexey Viktorovich, Candidate of Economic Sciences, Associate Professor of the chair "Finance", Penza State Agrarian University. Russia.

Kataev Oleg Gennadevich, Post-graduate Student of the chair "Biology, Biological Technology and Veterinarysanitarian Expertise", Penza State Agrarian University. Russia.

Meloyan Gayane Mkrtichian, Student of the Technology Faculty, Penza State Agrarian University. Russia.
Zemlyanova Julia Valerievna, Candidate of Biological Sciences, Penza Regional Cancer Center. Russia.

Kistanova Elena Kuzminichna, Candidate of Biological Sciences, Associate Professor Institute of Biology and Immunology of Reproduction at Bulgarian Academy of Sciences. Bulgaria.

Keywords: homogenate drone brood; mumps; testosterone; cortisol; body weight; average daily gain.

The influence of male bee brood homogenate on the level of testosterone and cortisol of swine has been studied, as well as their productive parameters. The inclusion of male bee brood homogenate in the diet of swine influenced the hormonal status, the growth rate of pigs evidenced by the increase in such indicators as live weight, average daily gain, percentage of slaughter yield of animals.

\section{ПРОДУКТИВНОСТЬ ЛУКА РЕПЧАТОГО ПРИ ПРИМЕНЕНИИ РЕГУЛЯТОРА РОСТА ЭНЕРГИЯ-М}

\author{
КАЛМЫКОВА Елена Владимировна, Волгоградский государственный аграрный \\ университет
}

ПЕТРОВ Николай Юрьевич, Волгоградский государственный аграрный университет

НАРУШЕВ Виктор Бисенгалиевич, Саратовский государственный аграрный

университет имени Н.И. Вавилова

Изучение действия регулятора роста на луке репчатом показало, что кремнийорганический препарат Энергия-М стимулирует рост и развитие растений, оптимизирует водопотребление и повышает продуктивность посевов. Выявлены наиболее перспективные для почвенноклиматических условий Нижнего Поволжъя гибриды лука репчатого, обладающие высокими адаптационнымивозможностями изначительнойпотенциальнойурожайностью. В полевомопыте проводились фенологические наблюдения, учет водопотребления и биологической урожайности, определение структуры урожая, массы товарного плода и товарности продукиии. Прибавка урожая лука репчатого от обработок препаратом Энергии-М составляла от 14,5 до 50,5 \%. При этом минимальная урожайность наблюдалась в варианте, где применяли только предпосевное замачивание семян лука на гибриде Октант $F_{1}-105,3 \mathrm{~m} / 2 а$. Максимальная величина урожайности получена на варианте комплексного использования препарата Энергия-М для замачивания семян и двукратного опрыскивания растений в рекомендованных дозах на гибриде Валеро $F_{1}-142,1 \mathrm{~m} / 2 a$.

Введение. Репчатый лук - одна из наиболее ценных, высоко витаминизированных овощных культур, широко распространенных в питании человека. Приготовление пищи без его использования невозможно, поскольку именно лук определяет вкус многих блюд. Его можно использовать не только в свежем, но и в сушеном, жареном, маринованном виде, охотно применяют в кулинарии и зеленые листья лука $[5,8]$. 